\title{
Questes
}

vestes Revue pluridisciplinaire d'études médiévales

$7 \mid 2004$

Les tabous

\section{Jaufre et l'Aventura, ou le tabou, métaphore de la mélancolie}

\section{Pierre Levron}

\section{(2) OpenEdition \\ 1 Journals}

Édition électronique

URL : http://journals.openedition.org/questes/2796

DOI : 10.4000/questes. 2796

ISSN : 2109-9472

\section{Éditeur}

Les Amis de Questes

\section{Édition imprimée}

Date de publication : 15 juin 2004

Pagination : 41-46

ISSN : 2102-7188

\section{Référence électronique}

Pierre Levron, « Jaufre et l'Aventura, ou le tabou, métaphore de la mélancolie », Questes [En ligne], 7|

2004, mis en ligne le 15 janvier 2014, consulté le 18 septembre 2020. URL : http://

journals.openedition.org/questes/2796 ; DOI : https://doi.org/10.4000/questes.2796

\section{(c) Association des amis de «Questes »}


Au moment où la satire est mise par écrit, peut-être surtout quand il s'agit des imprimés, elle doit être modifiée et transformée sous une forme plus abstraite et modérée ${ }^{x l v i}$. Nous pourrions considérer la scène du silence forcé dans des sotties et des pièces assimilées à la sottie comme un des moyens de dépasser l'horizon poétique et politique qui contraignait les auteurs de sottie. L'interdiction de la critique des particuliers dans la littérature satirique correspond à l'exigence des autorités tant ecclésiastiques que royales. Comme nous l'avons constaté, les sotties conservées laissent peu de place à ce qui va à l'encontre de cette interdiction. Par la même raison, il me paraît encore plus difficile d'y trouver des traces de ce qui est un tabou dans la société de la fin du $X V^{\mathrm{e}}$ et du début du XVIe siècle, d'autant plus que le critère de tabou est, nous semble-t-il, difficilement précisé par l'écrit, contrairement au cas de l'interdiction. Le silence des sots niais est l'un de rares éléments qui nous permettent d'imaginer ce qui relève de l'interdit ou, éventuellement, du tabou.

\title{
Jaufre et l'Aventura, ou le tabou, métaphore de la mélancolie.
}

\author{
Pierre LEVRON
}

Un épisode particulier du roman de Jaufre ${ }^{\text {xlvii }}$ permet de contribuer à la définition d'une forme littéraire des tabous au moyen-âge central. L'épisode où le chevalier parvient à la cour de Monbrun mobilise deux catégories de tabous: un 
interdit circonstanciel et un tabou beaucoup plus fondamental, la mélancolie du héros et du monde qui l'entoure. Il est organisé par une conjonction entre l'état intellectuel de Jaufre et la structure circonstancielle du récit. On rencontre en effet un monde « utopique », trop parfait pour être véritablement rassurant (vers 3072 à 3151) mais interdit, qui se caractérise par un conflit violent entre Jaufre et Brunissen, par les partisans de Brunissen interposés (le chevalier les affronte à trois reprises, avant qu'ils ne s'emparent de lui pour le conduire de force devant leur suzeraine, qui menace de l'exécuter). Jaufre n'a aucune conscience de cette interdiction, comme il ne sait pas qu'il a pénétré dans le verger. Les « codes » évidents pour la jeune femme (les oiseaux qui se taisent, donc qui dérogent à une habitude) ne sont pas perceptibles pour le chevalier. Il n'y a pas de transition sensible entre cet univers et le monde dont Jaufre est issu, à l'encontre de ce que l'on observe pour les milieux surnaturels, d'autant plus qu'il n'existe aucun «médiateur » entre l'individu et ce contexte. Le brouillage auditif est, lui aussi, totalement inconscient pour le chevalier (à l'inverse de ses usages amoureux). On observe une dissolution de la conscience de Jaufre. Il arrive involontairement dans le verger, en proie à une diversion mélancolique «surdéterminée » (fatigue physique et concentration obsessionnelle sur la poursuite de Taulat). L'intervention brusque des chevaliers qui le combattent successivement matérialise une invasion du psychisme par la mélancolie d'autant plus violente que le personnage dort et qu'on le réveille à quatre 
reprises. Un conflit s'instaure entre une mélancolie collective très violente, soulignée d'ailleurs par la beauté de la dame et par l'exacerbation du « potentiel courtois » de la scène, et deux mélancolies individuelles positives, la conversion à l'amour de Jaufre et de Brunissen. Ce tabou «dramatique » (entrer dans un univers interdit et saturé par la mélancolie) suppose une confrontation avec un tabou «circonstanciel» qui «matérialise » la mélancolie collective de Monbrun. Les lamentations collectives servent à la fois de « révélateur » et de phénomène déclenchant l'interrogation. Si elles sont évoquées chez Brunissen tout d'abord (vers 3151 à 3161), elles concernent l'ensemble de ses sujets (vers 3167 à 3170 ). Leur caractère régulier (trois fois par nuit: vers 3157 et 4598) est visible ensuite à la cour (vers 3817à 3832; 3916 à 3934; 4027 à 4033), et à l'extérieur (vers 4346 et 4347). Elles se produisent dans un milieu courtois et rassurant (la compagnie des fils d'Augier d'Essart, vers 4390 à 4397) aussi bien que dans le contexte très anxiogène de la cour. Elles sont déclenchées par une intervention extérieure (le cri du guetteur : vers 3818, 3916, 4027), même si elles peuvent aussi se manifester comme un « réflexe » (vers 4346, 4390). Elles possèdent un effet « révolutionnaire » qui présente deux aspects: l'interruption de l'action immédiate (vers 3162 à 3166; 3816 à 3820; 4394 à 4397) et l'apparition d'une tension logique violente entre cette interruption et le comportement de Jaufre, qui n'interrompt pas son activité présente (les lamentations accélèrent même sa fuite, vers 4034 à 4039). Le tabou proprement 
dit est perceptible par la fureur qui s'empare de tous ceux que Jaufre interroge. Elle a un effet très comparable à la clameur, dans la mesure où elle provoque une inversion de l'action, sensible lors des deux rencontres « courtoises » (avec le bouvier et la famille d'Augier d'Essart). Surtout, la question provoque toujours une réaction délirante, qu'elle soit posée alors que les lamentations ont lieu (vers 3484 à 3486; 4398 à 4401) ou en dehors de toute clameur, quand les interlocuteurs de Jaufre sont sereins (vers 4307 à 4309; 4667à 4672); l'interrogation se substitue fonctionnellement à l'appel de la clameur, dès lorsqu'elle provoque une crise mélancolique circonstancielle ou aggrave celle que les personnages éprouvent. Elle cause des saturations atrabilaires temporaires qui se traduisent par des actes très violents: l'agressivité de personnages frappant violemment Jaufre, caractéristique d'autres récits de fureur collective ( la « fable» de Peire Cardenal Una Ciutat fo, no sai quals..., vers 3842 à 3851) ou lui lançant ce qu'ils trouvent sous la main (vers 4312 à 4315,4320 ; 4405) jointe à une fureur meurtrière et destructrice qui se substitue à la mort dont Jaufre est menacé ou réputé et qui frappe des animaux (vers 4331et 4332; 4412) et des objets (vers 4326 à 4330) ainsi qu'à une «autoagressivité » traduite par l'acte de déchirer ses vêtements, préliminaire fréquent à la démence (vers 4101 à 4103; 4324; 4695 à 4702) et qui signe l'échec de l'intention furieuse. Dans tous les cas, des insultes précèdent l'agression. Ces trois épisodes de révolution furieuse reposent sur un conflit entre une logique 
« extérieure », celle de Jaufre, qui maintient une perspective médiatrice courante, et celle d'un univers fondé sur une discrimination entre lui et le monde extérieur aussi absolue qu'imperceptible. La logique commune, « importée » par le chevalier, est « désactualisée » sans qu'il ne le sache, et très nettement infléchie par l'instauration d'un questionnement obsessionnel à propos de ces clameurs (vers 4333 à 4343; 4655 à 4660). La contagion mélancolique passe donc par la confrontation de l'esprit à un tabou nanti de caractéristiques orthodoxes: violemment réprimé quand il est formulé, il transforme une question originelle en obsession. Le lien entre l'interdit fondamental (imperceptible) et l'interdit le plus visible se fait par cette confrontation entre une logique mélancolique unanime et parfaitement rigoureuse et un esprit qui interprète comme des ruptures des états étroitement complémentaires. L'épisode articule en fait une tension entre la conception implicite de la mélancolie chez Jaufre (une crise extérieure, qu'il doit résoudre) et celle qui définit le parcours initiatique du personnage (l'individu est lui-même confronté à des épreuves mélancoliques inquiétantes). Le tabou réel est alors constitué de deux éléments : le «tabou extérieur», auquel le chevalier est confronté, et le « tabou intérieur » perceptible par les instances extradiégétiques, c'est-à-dire le péril atrabilaire. Leur résolution est strictement commune, la défaite de Taulat face à Jaufre (vers 6036 à 6070) suivie de la condamnation du chevalier criminel par la cour d'Arthur (vers 6654 à 6684) concrétisant la 
victoire de Jaufre sur un risque mélancolique intime (directement affronté lors du combat avec le chevalier noir, vers 5474 à 5840). Le récit propose une vision d'un tabou particulièrement complexe, dans la mesure où il repose sur une définition immédiate qui ne permet pas de l'apprécier totalement. Un spectacle superficiel sert à mettre en évidence une réalité fondamentale, celle d'une mélancolie qui est taboue parce qu'on ne la revendique pas et parce que l'on n'en fait pas l'objet direct du discours littéraire alors qu'elle est particulièrement présente dans la littérature du Moyen Age central. 